studies. There certainly still is mistrust of, and in some cases contempt for, the descriptive sciences based as they are on perception. Possibly this is because perception is often inseparable from sensations of beauty, and because it cannot always be entirely freed from value judgements. Aesthetic response is an integral part of observation. This is no more apparent than in the extraordinarily beautiful photographs in this book. Sybille and Klaus Kalas took these photographs as part of their research programmes, yet they are hauntingly beautiful.

In a characteristically modest way, Lorenz says that the text was written merely to accompany the photographs, the real story being told by the photographs themselves. This is perhaps too modest, for explanation is an essential part of the book, and the text is informative, simple and often witty. I unreservedly recommend this book.

P.J.S. OLNEY

\title{
The Irish Wildlife Book, edited by Fergus O'Gorman, illustrated by Gerritt van Gelderen, Eamon de Buitear and Richard Mills. John Coughlan, £5.50.
}

Ireland has not, until recently, been associated with the leaders in the field of conservation, but if the recent dramatic increase in interest and activity continues, it will soon be an example to the rest of the world. At present the movement is small enough not to get bogged down with bureaucracy and paperwork, and the enthusiasm of a young and vigorous movement is certainly apparent in the 159 pages of this book. I can think of no other book to compare it with. It is truly an Irish wildlife book - no two chapters seem related, yet under Fergus O'Gorman's skilful editorship, it has come together as a remarkable overview of wildlife and conservation, assembled not only with science in mind, but also with an eye for the visual appeal and a considerable amount of wit and charm. Gerrit van Gelderen's 'comic strips' deserve to be reprinted as posters and leaflets; not only are they very instructive, but they teach with humour. Apparently the book was started on September 11979 - and in the bookshops by Christmas - in itself a remarkable achievement. It is published in conjunction with the Irish Wildlife Federation, An Taisce and the Irish Wildlife Conservancy, and they all deserve to have new members flocking to them as a result of this book. The 27 chapters range across 'Megaceros to Mink' to 'Salmon', from 'The Burren, the Fertile Rock', to 'Dublin's Nature Paradise', and from 'Wetlands are not Wastelands' to 'A Whale of a Tale'. It would be a narrow-minded naturalist who would not find something to delight in here.

JOHN A. BURTON

\section{Wildlife of Scotland, edited by F.H. Holliday. MacMillan, £8.95.}

For both amateurs and professionals Scotland has few parallels in the opportunities it offers for studying wildlife. Many of its attractions are obvious - its beauty and isolation, the diversity of habitats and the wide variety of animals that occupy them. Equally important are its practical advantages, including the accessibility of its wilderness areas, the good visibility offered by moorland habitats and the extensive knowledge of topography, geology and botany that already exists. Small wonder then that studies of Scottish wildlife have a long and distinguished history and that, arguably, more is known about the plant and animal populations of Scotland than about those of any other country of similar size and population density.

Wildlife of Scotland provides a review of our present knowledge. It is divided up on the basis of habitats: the first seven chapters cover the biology of the uplands and lowlands; of forests and woodlands, lochs, rivers and estuaries, while the last three chapters deal with more specific topics, the Hebrides and the offshore islands, Scottish mammals, and interactions between plants and people. Fred Holliday, former Chairman of the Nature Conservancy Council, has been able to call on a formidable array of talent, and each of the ten authors is an expert in his or her field. The result is a detailed but readable account of the current state of knowledge of the ecology of 